\title{
Commentary
}

\section{Dread Risk, September 11, and Fatal Traffic Accidents}

\section{Gerd Gigerenzer}

\author{
Max Planck Institute for Human Development, Berlin, Germany
}

\begin{abstract}
People tend to fear dread risks, that is, low-probability, high-consequence events, such as the terrorist attack on September 11, 2001. If Americans avoided the dread risk of flying after the attack and instead drove some of the unflown miles, one would expect an increase in traffic fatalities. This hypothesis was tested by analyzing data from the U.S. Department of Transportation for the 3 months following September 11. The analysis suggests that the number of Americans who lost their lives on the road by avoiding the risk of flying was higher than the total number of passengers killed on the four fatal flights. I conclude that informing the public about psychological research concerning dread risks could possibly save lives.
\end{abstract}

People tend to avoid situations in which many people may be killed at one point in time, as opposed to situations in which the same number may be killed, but the deaths are distributed over a longer period of time (Slovic, 1987). The former low-probability, high-consequence events are called dread risks. The crash of four planes in the terrorist attack of September 11, 2001, exemplifies such a catastrophic event. Avoiding a dread risk, however, may cost lives. Myers (2001) suggested that the disastrous events of September 11 may have led to a second toll of lives, but at that time he had no data to test this tragic possibility. Let me formulate the hypothesis first, and then provide a test.

If (a) Americans reduced their air travel as a consequence of September 11 and (b) a proportion of those who reduced their flying instead drove (as opposed to staying home or taking a train), then (c) an increase in traffic fatalities would have resulted. I call this the "dread" hypothesis, for short. The evidence supports the first part of the hypothesis. Millions of Americans stopped or reduced their air travel, which left airlines and travel agencies flying into the red. For instance, the national revenue passenger miles decreased in October, November, and December 2001 by $20 \%, 17 \%$, and $12 \%$, respectively, compared with the same months in 2000 (Air Transport Association, n.d.). Direct evidence for the second part of the hypothesis, in contrast, is difficult to obtain, because there is no record of how many

Address correspondence to Gerd Gigerenzer, Max Planck Institute for Human Development, Lentzeallee 94, 14195 Berlin, Germany; e-mail: gigerenzer@mpib-berlin.mpg.de. people decided not to fly and to drive instead. Indirect evidence can be obtained from the Office of Highway Policy Information (U.S. Department of Transportation, 2003a, 2003b), which reported the number of vehicle miles driven in the United States before and after September 11. The monthly miles driven in 2001, compared with 2000 , were on average $0.9 \%$ higher before September 2001, but $2.9 \%$ higher in October, November, and December 2001. ${ }^{1}$ In these 3 months, the largest traffic increase occurred on rural interstate highways (5.3\%), which is consistent with the hypothesis that longdistance travel increased.

There is a regularity that makes a test of the dread hypothesis feasible. The fatality numbers for the preceding 5 years, 1996 to 2000 , were highly stable; they followed a regular pattern from January through December, and the yearly totals were also fairly constant (National Highway Traffic Safety Administration, 1996, 1997, 1998, $1999,2000,2001)$. This stable pattern can function as a reference. The third part of the dread hypothesis can thus be formulated as follows: First, in the months before September 2001, the number of fatal crashes followed the numbers for the previous 5 years, plus or minus a constant that reflects a general increase or decrease in 2001. Second, in the last 3 months of the year, that is, the months following September, the number of fatalities no longer corresponded to the monthly average, plus or minus the constant, but instead rose to a consistently higher level.

Figure 1 shows that the number of fatal crashes from January through August 2001 closely followed the numbers for the 5 preceding years. The average deviation of the 2001 figures from the means in 1996 through 2000, for the months before September 11, is as low as 9 fatal crashes per month, which corresponds to $0.3 \%$ of the monthly total. A small average deviation would nonetheless mean little if there were a large variability across the months. In each of these 8 months, however, the value for 2001 was within the range of the previous years (the vertical black bars in Fig. 1). Thus, before September 2001, the number of crashes corresponded very closely with both the average and the variability of the previous 5 years.

This conformity did not hold for the last 3 months of 2001. Two kinds of comparisons indicate that the number of fatalities no longer conformed to the pattern before September 11: comparisons of

${ }^{1}$ The data for 2000 are taken from the Federal Highway Administration report from February 14, 2003 (U.S. Department of Transportation, 2003a), and the data for 2001 are taken from the updated report from March 4, 2003 (U.S. Department of Transportation, 2003b). 


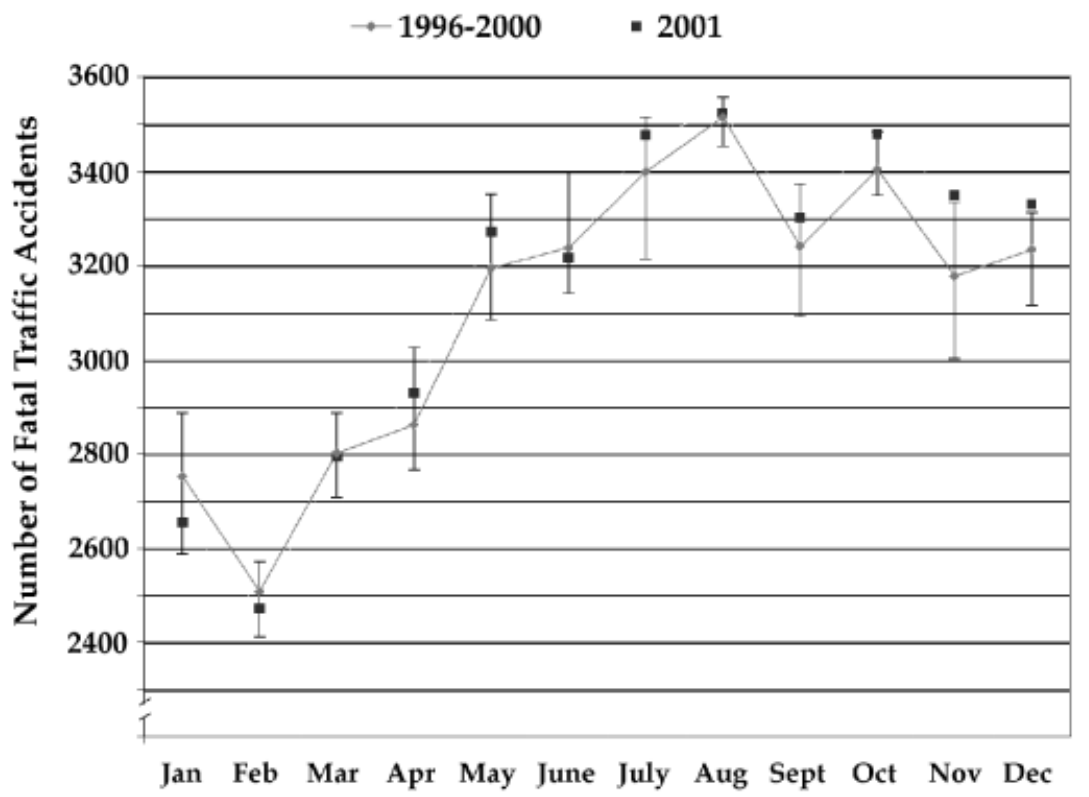

Fig. 1. Number of fatal traffic accidents in the United States in 1996 through 2000 versus 2001. The gray line represents the means for the years 1996 through 2000 , the vertical black bars indicate the highest and lowest values for those years, and the black squares indicate the values for 2001 .

absolute numbers of fatal traffic accidents in the last 3 months of 2001 versus the previous 5 years and comparisons that take into account the average increase in the first 8 months versus the last 3 months of 2001 compared with the previous 5 years. The numbers of fatal traffic accidents in October through December 2001 are consistently at or above the upper range of the previous years. The increase is consistently higher than the average increase of 9 fatal crashes per month in the months before the terrorists' attack. One can calculate the expected numbers of fatal crashes under the hypothesis that the last 3 months of 2001 had the same small average increase of 9 crashes (i.e., September 11 had no effect) and compare them with the observed numbers. The result is a significant surplus of $317(67+163+87)$ fatal crashes for the last quarter of the year, $\chi^{2}(3, N=10,157)=12.0$, $p=.008$. Because the ratio of fatalities to fatal crashes was $42,116 /$ 37,795 in 2001, the excess in crashes corresponds to some 353 fatalities.

This number of about 350 lost lives is an estimate of the price Americans paid for trying to avoid the risk of flying. The estimate is for the 3 months following the attack, and when the data for 2002 are available, we will be able to see for how long they paid this price. Terrorism causes fear, an emotion we all have felt after the tragic circumstances in which 266 passengers and crew members (as well as many more people at the scenes of the attacks) were killed in the four fated flights. That same fear, however, seems to have caused a second toll of lives, which has apparently gone unnoticed. Preventing terrorist attacks is difficult, and governments all around the world are focusing on this task. Avoiding the second, psychologically motivated toll could be comparatively easy and inexpensive, if the public were better informed about psychological reactions to catastrophic events, and the potential risk of avoiding risk.

\section{REFERENCES}

Air Transport Association. (n.d.). ATA monthly passenger traffic report: Revenue passenger enplanements and revenue passenger miles. Retrieved May 22, 2003, from http://www.air-transport.org/public/industrie/displayl.asp?nid $=1037$

Myers, D.G. (2001, December). Do we fear the right things? American Psychological Society Observer, 14, 3 .

National Highway Traffic Safety Administration. (1996). Traffic safety facts. Washington, DC: Office of Traffic Safety Programs.

National Highway Traffic Safety Administration. (1997). Traffic safety facts. Washington, DC: Office of Traffic Safety Programs.

National Highway Traffic Safety Administration. (1998). Traffic safety facts. Washington, DC: Office of Traffic Safety Programs.

National Highway Traffic Safety Administration. (1999). Traffic safety facts. Washington, DC: Office of Traffic Safety Programs.

National Highway Traffic Safety Administration. (2000). Traffic safety facts. Washington, DC: Office of Traffic Safety Programs.

National Highway Traffic Safety Administration. (2001). Traffic safety facts. Washington, DC: Office of Traffic Safety Programs.

Slovic, P. (1987). Perception of risk. Science, 236, 280-285.

U.S. Department of Transportation, Federal Highway Administration. (2003a). Table 1-Estimated individual monthly motor vehicle travel in the United States [2000-2001 data]. Retrieved May 22, 2003, from http://www. fhwa.dot.gov/ohim/tvtw/nov_tvt/tablel.htm

U.S. Department of Transportation, Federal Highway Administration. (2003b). Table 1-Estimated individual monthly motor vehicle travel in the United States [2001-2002 data]. Retrieved May 22, 2003, from http://www. fhwa.dot.gov/ohim/tvtw/02dectvt/tablel.htm

(RECEIVED 3/28/03; REvisIon ACCEPTED 6/10/03) 